\title{
Saving More than Lives: A Gendered Analysis of the Importance of Fertility Preservation for Cancer Patients
}

\author{
Lisa Campo-Engelstein ${ }^{1}$, Sarah Rodriguez ${ }^{2}$ and Shauna Gardino ${ }^{2,3}$ \\ ${ }^{1}$ Alden March Bioethics Institute \& Department of OBGYN, \\ Albany Medical College, \\ ${ }^{2}$ Northwestern University, Feinberg School of Medicine, \\ ${ }^{3}$ Oncofertility Consortium
}

USA

\section{Introduction}

Cancer affects millions of Americans annually. Men's lifetime risk of developing cancer for all sites is 50\%; women's lifetime risk is just over 33\% (American Cancer Society, 2009). While cancer is generally perceived as a condition affecting people past their child-bearing years, nearly $10 \%$ of those diagnosed are under age 45 (Horner et al., 2009). Indeed, some of those diagnosed with cancer are still children. In 2006, an estimated 9,500 new cases of pediatric cancer were diagnosed in the United States (American Cancer Society, 2006). Because of recent breakthroughs and more aggressive treatments, the survival rate of those diagnosed with childhood cancer has risen to almost 80\% (Clayman, Galvin, and Arnston, 2007). One estimate is that by 2010 one of every 250 adults will be a survivor of childhood cancer (Kinahan, 2007).

But while more aggressive treatments have meant more people survive cancer, these treatments have also resulted in impaired fertility or sterility for some. Given the numbers of children and adults within their child-bearing years diagnosed with, treated for, and surviving cancer, fertility concerns have emerged as a quality of life issue important to cancer survivors and their families. In one study of cancer survivors, $76 \%$ of those who were childless expressed a desire to have children in the future (Schover, 2009). Impaired fertility as a result of cancer treatment has physical as well as psychological effects. The existing literature on women whose fertility was impaired as a result of cancer treatment reveals an intense psychological distress; for these women, "psychological distress may result from, not only the loss of the physical ability to conceive, but also a symbolic loss of the option or idea of fertility, regardless of whether this would have been acted upon or achievable" (Carter et al, 2005, p. 93). Some studies on men have revealed similar levels of long-term distress over their impaired fertility as a result of cancer treatments (Schover, 2009) while other studies found that infertility is not nearly as devastating for men as it is for women.

Though reproduction is valued by both women and men, as the conflicting responses to studies between women and men (and even among men) illustrate, there are often 
differences in how women and men respond to infertility. Gender has been the focus of much analysis in ethics, but little work has been done looking at gendered narratives to analyze fertility concerns as a quality of life issue among men and women undergoing possible fertility-impairing treatment for cancer. Such an analysis is relevant in the current context because of the rise in the number of younger people being diagnosed with and surviving cancer and accompanying scientific and technological advances in fertility preservation techniques. In the context of cancer survivorship, fertility has become a distinct quality of life consideration, with an entire new field (oncofertility) now dedicated to promoting fertility preservation options for cancer patients and survivors. Since oncofertility is a novel discipline that bridges a variety of academic scholarships, existing conceptual frameworks are inadequate for analyses within this field. We propose a multidisciplinary approach to understand the gendered themes of infertility as a quality of life concern in the current context of oncofertility.

In doing so, we argue that exploring common cultural conceptions of gender is essential to understanding cancer patients' and their families' fertility preservation decision making when confronting potential infertility. Our analysis begins at the patient level with a discussion of the existing literature that describes gender differences among cancer patients regarding fertility, cancer treatment, and the effects of both on their quality of life. Uniquely, we contextualize these existing social science studies within a historical context, using a new perspective to attempt to explain the sometimes divergent responses between women and men and among men by focusing on the different ways men and women have been treated for infertility broadly since the nineteenth century. We build on this historical framework by conducting a gendered analysis of infertility and fertility choices that is centered in the current cultural climate. In this way, we address gender, infertility, and fertility choices from three distinct levels - the individual level, the contextualizing historical level, and the broader current cultural level - creating our own multidisciplinary framework. Our analysis offers an insightful approach, creating a new framework within which we are able to draw meaningful conclusions about the impact gendered responses to infertility have on cancer patients' medical care and how health care providers and researchers can incorporate this knowledge to improve patient care.

\section{Fertility preservation technologies}

The developing field of oncofertility is dedicated to providing fertility preservation options to cancer patients, and a number of alternatives currently exist for both men and women. Reproductively mature men confronting a cancer diagnosis can generate a sperm sample and cryopreserve (freeze) their gametes for later use. Ejaculation can be stimulated in young men and those too sick to produce a sperm sample, or an experimental testicular biopsy can be done; the resulting sample can be cryopreserved. The technology for freezing sperm is wellestablished and successful, leaving these men with a viable option to become a biological father after cancer. Freezing sperm is relatively inexpensive and easy to accomplish, thus a feasible option for men of all socioeconomic backgrounds and cancer types.

Women's reproductive potential can also be jeopardized during cancer treatment. The only established method of fertility preservation for women is embryo banking, but this is often not a palatable option for young and/or single women. Egg banking is gaining popularity because there is no reliance on a male donor (known or anonymous); however, it is still 
considered an experimental intervention by the American Society for Reproductive Medicine (ASRM). Neither embryo nor egg banking, however, are not good options for some newly diagnosed cancer patients because these procedures require a two-to-three week delay in cancer treatment and cannot be performed on those who have not yet reached puberty. For women or young girls for whom embryo or egg banking may not be an acceptable option, ovarian tissue cryopreservation offers another opportunity to protect their potential to parent. Ovarian tissue cryopreservation is a procedure in which one ovary is removed and ovarian tissue is frozen in small strips. Based on the woman's treatment plan, the strips can be transplanted back and potentially restore ovarian function. Researchers are also currently working on another way to use the tissue: maturing the follicles from the cryopreserved ovarian tissue within the laboratory. As the functional unit of the ovary, the follicles would ideally mature into eggs and then be fertilized, with the resulting embryo implanted back into the woman when she desires pregnancy (Jeruss and Woodruff, 2009).

\section{Examining the existing research on QOL and fertility}

As we will discuss in-depth in the next section, infertility has historically been associated with women. Indeed, early studies of fertility concerns among cancer patients and survivors claim that women value fertility to a greater extent than men. In 1987, Wasserman, Thomspon, Wilimas, and Fairclough (1987) determined that attitudes toward possible sterility differed dramatically between female and male Hodgkin's survivors, with females expressing much more concern about their childbearing potential than males. Five years later, Zelter published a literature review, concluding that women as a group seek more information and evaluation of their fertility status than men (Zelter, 1993). Schover, Rubicki, Martin, and Bringelsen (1999) followed up with another literature review, hypothesizing from gathered data that women are more distressed over infertility, more concerned about having children, and more likely to see parenthood as an integral part of their life goals when compared to men. Finally, Patridge et al (2004) found that women will even sacrifice the efficacy of cancer treatment to lessen their chances of infertility or sterility, describing how, if given a choice, young women with early-stage breast cancer may choose a less toxic regimen of chemotherapy even if it confers slightly less protection from recurrence of cancer.

However, a handful of studies have recognized that male cancer patients and survivors value their fertility as well. A 1990 study by Reiker et al of 153 testicular cancer survivors indicated that distress about infertility is also prevalent among men, particularly among those who have cancer treatments that are likely to severely impair fertility (Reiker, 1990). Similarly, a 2003 study by Green, Galvin, and Horne confirmed that infertility can cause long-term distress among men with cancer. The literature regarding fertility concerns among male cancer patients is scarce when compared to the number of studies that demonstrate the importance of fertility among female cancer patients, but nonetheless this data should not be ignored. A growing body of more recent literature is beginning to recognize fertility concerns among male cancer patients, concluding that gender differences in fertility concerns may not be as prominent as once thought.

Indeed, a 1999 study by Schover et al, which used a questionnaire to examine 283 young cancer survivors, found that about $80 \%$ of cancer survivors viewed themselves positively as 
actual or potential parents, with no observed gender-related differences in the wish to have children or distress about fertility (Schover, et al, 1999). Similarly, a 2004 study by Zebrack, Casillas, Nohr, Adams, and Zelter used semi-structured interviews to assess the impact of cancer on long-term cancer survivors' quality of life, concluding that both men and women expressed a desire to have children in the future (Zebrack, 2004). Finally, an exploratory qualitative study by Crawshaw (2010) found that fertility matters affected identity, wellbeing and life planning as well as reproductive function, regardless of gender.

Our literature review of gender differences in fertility concerns among cancer patients indicates that, at present, there is conflicting evidence, but understandings of these gendered differences may be changing. While older studies indicate that female cancer patients value their fertility more strongly than male cancer patients, newer research suggests that these attitudes may be changing as more male cancer patients are beginning to recognize and express their fertility-related distress. However, these disparate conclusions could also be explained by differing methodologies; the aforementioned studies range from semistructured interviews to questionnaires to literature reviews. As these studies are rooted in distinct and differing methodologies, drawing accurate comparisons between them may be complicated.

In the rest of the paper we explore factors that may account for the aforementioned discrepancies in the literature relating to fertility concerns among female and male cancer patients, using both historical and cultural frameworks to explain how these attitudes are developed and derived.

\section{Historical foundations: Women and infertility}

In order to better understand the basis for the differing ways women and men may view infertility today, and the lack of consensus about the value of fertility among men, we need to explore the differences in the ways men and women have been medically treated for infertility in this country. As we will next describe, medical treatment for infertility in the United States reinforced and reflected prevailing cultural ideas about masculinity and femininity.

Though Americans could consult medical guides in the late eighteenth century for recourse to alleviate an involuntarily childless marriage, it was during the nineteenth century when physicians became increasingly involved in treating, and patients began to increasingly seek medical intervention for, infertility (Marsh and Ronner, 1996). Almost always, however, the patients seeking treatment were women. Why? Though motherhood had earlier been a principal role for women, during the nineteenth century it increasingly became the defining role for women, especially white middle-class women (Apple, 1997; Marsh and Ronner, 1996). By the early nineteenth century, American society began to draw clearer lines between family and community. These lines changed how families were seen and composed, both of which had profound implications for women's conceptions of femininity and reproduction. During the course of the nineteenth century, biological parenthood rather than household composition came to define a family, and thus being a mother increasingly meant bearing one's own children. As part of this shift, biological motherhood was increasingly regarded as the primary and principal role of women - in contrast to women in colonial America, where motherhood, though important, was seen as only one of a woman's 
roles (Marsh and Ronner, 1996). Being a mother, especially through pregnancy, began to be more strongly tied to being a woman. This change in the stress placed on biological motherhood as the core identifier for femininity, along with the rise in the profession of gynecology, prompted a change in the way involuntary childlessness was viewed, both popularly and medically. What had been regarded as barrenness, a personal misfortune, became infertility, a treatable condition. As Margaret Marsh and Wanda Ronner (1996) noted in their history of infertility in the United States, during the nineteenth century, involuntarily childless married women began to increasingly turn to medical expertise; by doing so, both clinicians and women accepted infertility as treatable. Infertility was now a recognized medical condition, but patients seeking treatment for it were still nearly all female (Marsh and Ronner, 1996).

Beginning in the late nineteenth century, Marsh and Ronner argue, women willingly underwent often invasive treatments, including various surgeries, to correct an impairment of their bodies in order to provide them with a chance for motherhood. By doing so, they sought a surgical restoration not just of their reproductive functions but also of their feminine identity. The convergence of motherhood as defining femininity with the increasing reliance on physicians to treat involuntarily childless women enabled a perception that infertility was a problem of and with the female body. This was reinforced as only women sought medical attention for infertility. For the majority of the nineteenth century, it was women alone who were considered, culturally and medically, to be infertile; men were only considered infertile if they were impotent (Marsh and Ronner, 1996). Infertility was characterized as a disease of the female body, and it was a disease that impaired a woman's ability to achieve her primary social role: motherhood (Apple, 1997; Marsh and Ronner, 1996). Women internalized infertility: a woman's inability to biologically bear children challenged the prevailing cultural norm that motherhood was the natural role for a feminine woman. Infertility, then, affected the way women saw their feminine selves.

As Marsh and Ronner (1996) found when they examined infertility in the late nineteenth and early twentieth centuries in the United States, doctors treated women across racial, ethnic, and class lines, suggesting the link between reproduction and femininity extended across the demographic spectrum. As the twentieth century wore on, increasing numbers of women sought medical expertise to enable them to conceive, with a sharp rise in infertility treatments accompanying the baby boom following World War II. During this intense pronatalist period in American history, to not be pregnant or have children within two years of marriage marked some women as odd - possibly even suggesting a lack of femininity. This tie between a woman's ability to conceive and her femininity, though ebbing a bit in the 1970s, remained strong through the course of the twentieth century (Marsh and Ronner, 1996; May, 1995).

\section{Current cultural narratives: Women and infertility}

The cultural connection between a woman's reproductive ability and her feminine identity has strong historical foundations in how women have been treated for infertility, foundations that continue to frame cultural conceptions of femininity as well as individual women's conception of themselves as female. Women have, and continue to, internalize their infertility. The contemporary literature on women without a cancer diagnosis but with 
impaired fertility reveals a significant amount of stress and depression due to their condition. Women who are infertile but otherwise healthy are twice as likely to be depressed as fertile healthy women; indeed, these women report levels of psychological distress comparable to women with life-threatening illnesses (Davis and Dearman, 1991; Domar, Zuttermeister, 1993; Luske and Vacc, 1993). In her exploration of women's reactions to learning of their infertility, Gayle Letherby (2002) found that women experienced a profound shock to their sense of themselves, resulting in a challenge to their conception of identity as female.

What happens, then, to a woman's conception of herself when the option for biological motherhood is impaired or taken away because of her cancer diagnosis or cancer treatment? The existing literature on women whose fertility is impaired due to cancer treatment reveals similar psychological stress; for these women, "psychological distress may result from, not only the loss of the physical ability to conceive, but also a symbolic loss of the option or idea of fertility, regardless of whether this would have been acted upon or achievable" (Carter, et al., 2005, p. 93). The American Society of Clinical Oncology (ASCO) found that "surveys of cancer survivors have identified an increased risk of emotional distress on those who become infertile because of their treatment" (Lee et al., 2006, p. 2921). One study on young women with breast cancer found that "fertility concerns may complicate" their "treatment decision-making process" and that there is evidence these young women "may experience greater psychological distress and more difficulty with adjustment to the diagnosis and treatment of breast cancer" (Partridge, 2004, p. 4175). This actual or symbolic loss has potentially great implications for a woman's perceptions of herself as female, for motherhood is a culturally significant role most women see themselves in and which cancer potentially interrupts. Women whose cancer treatments threaten their fertility still want the experience of motherhood, most often biological motherhood (Lee et al., 2006, p. 2921). This equation of femininity with reproductive ability remains culturally resonant. Women today, as in the past, quite often tie their feminine identities to their reproductive capabilities; a cancer diagnosis is a recent, and additionally culturally powerful, component of a longer story concerning women, infertility, and medical treatment.

\section{Historical foundations: Men and infertility}

Women, as was just explored, were much more likely in both the nineteenth and the twentieth centuries to seek medical treatment for infertility. While this gender discrepancy was at first an outgrowth of the idea that only women were barren, and then that only women were infertile, it persisted even as physicians noted that there could be a male factor involved in infertility. Indeed, by the late nineteenth century, some gynecologists began calling for husbands to be examined when wives came seeking a cure for their childlessness. But even as the concept of barrenness gave way to infertility for women in the nineteenth century, very few doctors asked to examine a patient's husband, as most physicians still considered it rare for a virile man to be infertile (Marsh and Ronner, 1996). This cultural conception was reflected and reinforced medically in the nineteenth century. In the early twentieth century, after examining a young woman who had been married for six years and came to him for "relief" of her suffering from infertility, physician Gustavus Blech (1903) took a swab of semen from the young woman's vagina and looked at it under a microscope. He found "not a spermatozoon in sight." But though he noted this physiological matter, and 
recommended to other physicians the need to look at the sperm of husbands' when a woman came to them for the treatment of infertility, he also stressed the importance of whether or not the man was "capable of performing the sexual act" when analyzing if the infertility was male or female factor (Blech, 1903, 45-46).

As the Blech case illustrates, male fertility was connected to virility through the twentieth century, even though physicians acknowledged that the viability of the semen was an identifiable factor. Though by the 1930s physicians recognized that infertility was comparable in both genders, and by the 1950s semen analysis had become a standard protocol for infertility intervention, women largely remained the focus of medical fertility treatment. More than one physician lamented in the first half of the twentieth century that too many of his peers were eager to first perform invasive procedures (such as surgery) on the wife before testing the viability of the husband's sperm (Marsh and Ronner, 1996; May 1995). But even with the knowledge that men were infertile as often as women, this gender difference in treatment continued for the course of the twentieth century. In 1963, the president of the American Society for the Study of Sterility (later called ASRM) explained at the group's annual meeting that such a protocol remained justified because many infertility specialists believed men were rarely infertile. But just as important, since women usually initiated medical treatment, their husbands were often left unexamined (May, 1995). So while the physiological knowledge was there and the understanding that men were as likely to be infertile as women was available, women were the ones being treated because they sought the medical intervention. Even if a physician could not find a physiological reason on the woman's body, both the woman and the physician frequently believed the impairment was with her body. From the nineteenth century to the present, women have most commonly sought medical intervention for infertility, often doing so in order to spare their husbands from possible humiliation - a humiliation based on the idea that an infertile man was an impotent man (Marsh and Ronner, 1996; May, 1995).

While femininity was tied to reproduction, and this tie held both culturally and medically over the course of the twentieth century, masculinity, in contrast, was tied to sexual virility. Here we are extending the work of Marsh and Ronner (1996) in their history of infertility in the United States to argue that there is a historical basis for the current differences of fertility-related distress among male cancer patients compared to female cancer patients: men's medical treatment was not so tied, and did not reinforce, infertility as an impairment of their bodies. When infertility was associated with men, it was generally seen as an impairment with virility.

\section{Current cultural narratives: Men and infertility}

Virility remains a significant component of cultural conceptions of masculinity and men's gendered identities. Sexual prowess is often seen as a way of proving one's masculinity. Furthermore, the male genitals are generally central to a man's coherent sexual identity (Gurevich et al., 2004), and are associated with stereotypical masculine traits like "strength" and "courage" (Szasz, 1998). Because of the personal, as well as social, significance of the male genitals, having "misfunctioning" (e.g. impotent, prematurely ejaculating, infertile) genitals or genitals that look "abnormal" (e.g. small penis, missing a testicle) can diminish men's sense of masculinity. For instance, in a ranking of the most humiliating experiences for college age men, the top three had to do with sexual function and the appearance of 
genitals: 1 . unable to maintain an erection during sex; 2 . losing a testicle to cancer; 3 . being teased about penis size (Mormon, 2000).

This trend holds true for men facing cancer, especially those with cancer affecting the genitals: listing the second most humiliating experience as losing a testicle to cancer highlights the deleterious effects cancer can have on men's self-worth and identity. A qualitative study on men with testicular cancer found that definitions of masculinity continue to be strongly tied to sexual performance and the appearance of "normal" genitals, both of which can be threatened by cancer and cancer treatments (Gurevich et al., 2004).

Whereas the centrality of virility and male genitals to men's sexual identity is supported in the literature (Gurevich, et al., 2004), the importance of fertility for men - the desire to have biological children and the role fertility plays in their identity - is not just ambiguous, but is often contradictory. As previously discussed, some studies found male cancer patients value their fertility as much as female cancer patients whereas other studies show that women value their fertility much more than men. Much of the broader literature on infertility in the general population, not just cancer patients, supports the latter finding. In his interviews with mainly white, middle-class, heterosexual married couples facing infertility, ${ }^{1}$ Arthur Greil (1991) found that the husbands were more likely to view the experience of infertility as disappointing, though not as a threat to their identity. The wives, in contrast, saw infertility as devastating, something that spoiled their identities and signified their role failure as woman, wife, and mother (Greil, 1991). Furthermore, in a review of the literature, Greil discusses how both qualitative and quantitative studies show that women react more negatively to infertility (e.g. have lower self-esteem, blame themselves for their infertility, feel defective, etc.) than men (Greil, 2010). Even when the couple is suffering from male factor infertility, most of the literature concludes that this does not seem to change men's response to infertility (Greil, 1997).

Given that infertility is not as devastating for men as impotence or abnormal genitals, it is not surprising that a diagnosis of sterility ranks lower (in fifth place) on the list of the most humiliating experiences for college men than experiences that are more closely connected to sexual performance and the appearance of "normal" genitals (Mormon, 2000)..$^{2}$ It is worth noting that men older than traditional college age students (18-22 years old) may have come up with a different ranking; while college age men are typically trying to avoid fatherhood and consequently do not value fertility as much at this stage in their lives, older men are probably more interested in becoming a father and thus may find a diagnosis of sterility more troubling.

While sterility and infertility may not top the list as the most humiliating experience for young men, they are still negative experiences. A large reason for this is the close relationship between men's virility and fertility (Inhorn, 2002). The historical association of infertility with impotence and the importance of virility to current conceptions of

\footnotetext{
1 White, middle-class, heterosexual married couples are the most common participants of many empirical studies on infertility in part because they are the social group most likely to seek out infertility treatment. In the last handful of years, however, more research has been done on people of color and infertility. See, for example, Becker et al., Jain, and White et al.

${ }^{2}$ Having a rectal exam ranks fourth. While this experience does not directly deal with male sexuality, being penetrated is usually associated with women, which is in part why this experience is humiliating.
} 
masculinity result in cultural understandings of infertility as an indicator of emasculation. Cynthia Daniels (2006), a political scientist researching the politics of reproduction, asserts that "the ability to biologically father one's children remains a hallmark of one's manhood, and infertility remains a source of masculine shame" (p.161). Specifically, questions about the viability of sperm production incite questions about the viability of masculinity (Gurevich 2004; Daniels 2006) This association is reflected in the secrecy and stigma surrounding heterosexual couples using sperm donation and results in practices like "matching" sperm donors to the physical traits and characteristics of the social father to hide his infertility (Becker, 1994; Daniels, 2006).

In addition to threatening masculinity, infertility may adversely affect men because it leaves their desire for biological children unfulfilled. Yet, this reason may play a smaller role for men than for women. The cultural pressure for women to have biological children and the fact that motherhood is an important part of many women's identity are thought to be a significant factor in why infertility is so devastating to women. That " $[t]$ here is, in American society, no 'fatherhood mandate' with the same force and intensity as the "motherhood mandate" may explain, at least in part, men's less strong reaction to infertility (Greil 1991, p. 64).

While there is still less pressure for men to be biological fathers compared to the pressure women feel to be mothers (at least in the U.S.), men are much more active in their children's lives than even a generation ago. We see this change reflected in new concepts and policies. For example, the concept of a stay-at-home dad is relatively recent. This term probably did not exist, or at the very least was not ubiquitous, a couple of generations ago. Today, the U.S. Census Bureau estimates that there are 143,000 stay-at-home dads. Men's involvement in primary caretaking of children is also seen in policies like extending maternity leave to men through paternity leave. A recent study shows that $89 \%$ of men took some time off after the birth of their child (Nepomnyaschy and Waldfogel, 2007).

Men's increased involvement in their children's lives shows not only that fatherhood is extremely significant for many men, but also that men's active participation in their children's lives is becoming more socially acceptable. Indeed, gender norms surrounding fatherhood are changing, which influences the value men place on becoming biological fathers. Fatherhood today seems to play a greater role in men's identity and their vision of an ideal life. This social change helps explain the mixed results on the importance of fertility to male cancer patients as illustrated in the quality of life surveys. We are in a time of transition in which more men are value active fatherhood, but there are still men who adhere to traditional gender roles. The survey results mirror this transition, as some surveys show that men are less interested in parenthood than women and other studies reveal that men's and women's interest in fertility are equivalent. If men's interest in fatherhood continues to grow, we can expect that in the future, studies will uniformly find that women and men equally value parenthood.

\section{Clinical implications and conclusions}

The persistent gender bias - women's bodies demand medical intervention while men's bodies are left alone as long as there is a physical sign of sexual potency - is a historically important cultural phenomenon that continues to shape current conceptions of femininity, masculinity, and fertility. Understanding the history of the differences in medical treatment 
of infertility provides a unique contextualization of contemporary cancer patients' views on their fertility and the possibility of their future infertility. Quality of life studies consistently show that fertility is very important to female cancer patients and while the results for male cancer patients are mixed, many men do strongly value their fertility. These social science studies, however, are often not translated into clinical practice by health care providers. Instead, many providers continue to make assumptions "based on the patient's age, sex, diagnosis, culture, and partnership status without checking with the patient" (Horden and Street, 2007, p. 227). Furthermore, providers' personal characteristics (e.g. age, sex, etc.) can also influence whether they discuss fertility preservation treatment with their patients. For example, a recent study found that female oncologists were more likely to refer their patients to a reproductive endocrinologist or infertility specialist compared to male oncologists. While discussions and referrals for fertility preservation among adult cancer patients are improving, they remain suboptimal: only forty-seven percent of respondents always or often refer cancer patients of childbearing age to a reproductive endocrinologist or infertility specialist (Quinn, 2009). Health care providers need to openly address potential infertility as a consequence of cancer treatment so that their patients are informed about and offered fertility preservation options.

By contextualizing female and male cancer patients' views on infertility within a historical framework, we have shown that these differences in views are not innate, but rather are shaped by gender norms, both historical and current. Understanding the social factors that influence people's views on infertility will enable health care providers to better aid their patients in their fertility preservation decision making. In other words, situating patients within their social environment, rather than seeing them as free floating individuals or reducing them to their diseases, allows providers to acknowledge the various social factors that contribute to and are at stake in decisions about fertility preservation treatment. Familiarity with gender norms as well as recognition they are changing (especially the role of fatherhood for men) equips providers with the ability to understand the discrepancy between women's and men's views and the discrepancy among men's views on infertility. This can help providers be more empathetic to their patients' needs and concerns, while at the same time not pigeonholing patients by sex/gender.

Various health organizations, including ASCO and ASRM, have issued guidelines on fertility preservation to their practitioners for all cancer patients stating that "the available evidence suggests that fertility preservation is of great importance to many people diagnosed with cancer" (Lee, 2006, p. 2921; Ethics Committee of ASRM, 2005). While it is important for these organizations to set guidelines, the mere existence and dissemination of guidelines may not be enough to make substantial changes in provider referrals for fertility preservation treatment. A deeper appreciation for the social factors involved in patients' views on infertility may engender greater change and specifically more referrals for fertility preservation treatment. Safeguarding fertility for cancer patients should be considered as important of a quality of life issue as breast reconstruction and hair replacement (Campo-Engelstein, 2010), and the options for fertility preservation should be part of the discussion regarding a patient's cancer treatment - regardless of gender. Doing so respects both women's and men's desire to be - or at least retain the possibility of being - biological parents.

The best way to ensure that these historical foundations and social factors are integrated into clinical care is through the development of an appropriate intervention. By creating 
both provider and patient education materials that contextualize fertility preservation choices within the social environments in which they occur, as well as offering patients coping strategies that recognize their unique gendered responses, we can help address relevant patient concerns and enhance decision-making capabilities. Jordan et al. (1999) has recognized that significant gender differences exist in coping strategies for infertility, and these differences need to be addressed in the development of patient education materials that offer coping strategies (Jordan, 1999). Both historically and presently, infertility has been described as a devastating diagnosis for cancer patients, both female and male. Recognizing and outlining the historical influences that have contributed in creating this distress, as well as the current social factors that reinforce it, is a step in the right direction. Incorporating these analyses into the development of interdisciplinary patient and provider education materials is the next step towards translating these findings into clinical practice.

\section{Acknowledgement}

This research was supported by the Oncofertility Consortium NIH 8UL1DE019587, 5RL1HD058296.

\section{References}

American Cancer Society. (2006). Cancer facts and figures 2006. Atlanta: American Cancer Society.

American Cancer Society. (2008). Cancer facts and figures 2008. Atlanta: American Cancer Society.

American Cancer Society. (2009). Cancer statistics 2009 presentation. http://www.cancer.org/docroot/PRO/content/PRO_1_1_Cancer_Statistics_2009_ Presentation.asp (October 12, 2009).

Apple, R. D., Golden, J. (1997). Introduction. In R. D. Apple and J. Golden (Eds)., Mothers and motherhood: readings in American history. Columbus: Ohio State University Press.

Bardwell, W. A., Profant, J., Casden, D. R., Dimsdale, J.E., Ancoli-Israel S., Natarajan, L., Rock, C.L., Pierce, J.P., and Women's Healthy Eating \& Living (WHEL) Study Group. (2008). The relative importance of specific risk factors for insomnia in women treated for early-stage breast cancer. Psychooncology, 17(1), 9-18.

Becker, G., M. Castrillo, Rebecca Jackson et al. (2006). Infertility among low-income Latinos. Fertility \& Sterility, 85(4): p. 882-7.

Becker, G. and R. Nachtigall. (1994) 'Born to a mother': The cultural construction of risk in infertility treatment in the U.S. Social Science \& Medicine, 39(4), 507-518.

Blech, G. M. (1903). The Practitioner's guide to the diagnosis and treatment of diseases of women. Chicago: M. Robertson.

Carter J, Rowland K, Chi D, et al. (2005). Gynecologic cancer treatment and the impact of cancer-related infertility. Gynecol Oncol, 97, 90-95.

Campo-Engelstein, L. "Consistency in Insurance Coverage for Iatrogenic Conditions Resulting from Cancer Treatment Including Fertility Preservation." Journal of Clinical Oncology 28.8 (March 10, 2010)

Carver, C. S. (1997). You want to measure coping but your protocol's too long: Consider the Brief COPE. International Journal of Behavioral Medicine, 4, 92-100. 
Chang V.T., Hwang S.S., Feuerman M., Kasimis B.S., Thaler H.T. (2000). The memorial symptom assessment scale short form (MSAS-SF). Cancer, 89(5), 1162-71.

Clayman, M. L., Galvin, K. M., and Arnston, P. (2007). Shared decision making: Fertility and pediatric cancers. In Woodruff, T. K. and Snyder, K. A., eds. Oncofertility: Fertility preservation for cancer survivors. New York: Springer.

Connell S., Patterson C., Newman B. (2006). A qualitative analysis of reproductive issues raised by young Australian women with breast cancer. Health Care Women, 27, 94-110.

Crawshaw, M. A., Sloper, P. (2010) 'Swimming against the tide' - the influence of fertility matters on the transition to adulthood or survivorship following adolescent cancer. European Journal of Cancer Care, Jan 19.

Daniels, C. R. (2006). Exposing men: The science and politics of male reproduction. New York, Oxford University Press.

Davis, D. C., Dearman, C. N. (1991). Coping strategies of infertile women. Journal of Obstetric, Gynecologic, \& Neonatal Nursing, 20 (3), 221-8.

DevCan: Probability of Developing or Dying of Cancer Software, Version 6.3.0 Statistical Research and Applications Branch, NCI, 2008. http:/ / srab.cancer.gov/devcan.

Duman, A. D., Zuttermeister, P.C., Friedman, R. (1993). The psychological impact of infertility. Journal of Psychosomatic Obstetrics and Gynecology, 14 (Suppl S. Dec.), 4552.

Dunn J., Steginga, S. K. (2009). Young women's experience of breast cancer: Defining young and identifying concerns. Psychooncology, 9, 137-146.

Ethics Committee of the American Society for Reproductive Medicine. (2005). Fertility preservation and reproduction in cancer patients. Fertility and Sterility, 83 (6), 16221628.

Green D. H., Galvin, H., and Horne, B. (2003). The psycho-social impact of fertility on young male cancer survivors: A qualitative investigation. Psychooncology, 12,141-152.

Greil, A. L. (1991). Not yet pregnant: Infertility couples in contemporary America. New Brunswick: Rutgers University Press.

Greil, A. L., et al. 2010. The experience of infertility: A review of recent literature. Sociology of Health $\mathcal{E}$ Illness, 32(1):140-62.

Gurevich, M., Bishop, S., Bower, J., Malka, M., and Nyhof-Young, J. (2004). (Dis)embodying gender and sexuality in testicular cancer. Social Science \& Medicine, 58, 1597-1607.

Heinemann, K., Ruebig, A., Potthoff, P., Schneider, H., Strelow, F., Heinemann, L. and Minh Thai, D. (2004). The menopause rating scale (MRS) scale: A methodological review. Health and Quality of Life Outcomes, 2, 45-52.

Horden, A. J., and Street, A. F. (2007). Communicating about patient sexuality and intimacy after cancer: Mismatched expectations and unmet needs. Medical Journal of Australia, 186(5), 224-227.

Horner, M. J., Ries, L. A. G., Krapcho, M., Neyman, N., Aminou, R., Howlader, N., Altekruse, S. F., Feuer, E. J., Huang L., Mariotto, A., Miller, B. A., Lewis, D. R., Eisner, M. P., Stinchcomb, D. G., Edwards, B. K. (eds). SEER Cancer Statistics Review, 1975-2006, National Cancer Institute. Bethesda, MD, http://seer.cancer.gov/csr/1975_2006/, based on November 2008 SEER data submission, posted to the SEER web site, 2009.

Jain, T. (2006). Socioeconomic and racial disparities among infertility patients seeking care. Fertility \& Sterility, 85(4): p. 876-81. 
Jeruss, J. S. and Woodruff, T. K. (2009). Preservation of fertility in patients with cancer. The New England Journal of Medicine, 360(9), 902-911.

Jordan, A., and Revenson, T. A. (1999). Gender differences in coping with infertility: A metaanalysis. Journal of Behavioral Medicine, 22(4), 341- 358.

Kinahan, K. E., Didwania, A., and Nieman, C. L. (2007). Childhood cancer: Fertility and psychosocial implications. In Woodruff, T. K. and Snyder, K. A. (eds). Oncofertility: Fertility preservation for cancer survivors. New York: Springer.

Letherby, G. (2002). Challenging dominant discourses: Identity and change and the experience of 'infertility' and 'involuntary childlessness'. Journal of Gender Studies, 11, 277-288 (ref. on pg. 279).

Lee, S. J., Schover, L. R., Partridge, A. H., Patrizio, P., Wallace, W. H., Hagerty, K., Beck, L. N., Brennan, L. V., Oktay, K. (2006). American Society of Clinical Oncology recommendations on fertility preservation in cancer patients," Journal of Clinical Oncology, 24 (18), 2917-2931.

Loscalzo MJ, Clark KL. The psychosocial context of cancer-related infertility. In: Woodruff TK, Snyder KA, editors. Oncofertility: Fertility Preservation for Cancer Survivors. New York: Springer, 2007:180-190.

Lukse, M. D., and Vacc, N. A. (1999). Grief, depression, and coping in women undergoing infertility treatment. Obstetrics \& Gynecology, 93 (2), 245-51.

May, E. T. (1995). Barren in the promised land: Childless Americans and the pursuit of happiness. New York: Basic Books.

Mormon, M.T. (2000). The influence of fear appeals, message design, and masculinity on men's motivation to perform the testicular self-exam. Journal of Applied Communication Research 28, 81-116.

National Cancer Institute. (2006). Facing forward: life after cancer treatment. Washington, DC: U.S. Department of Health and Human Services, National Institutes of Health.

Nepomnyaschy, L. and Waldfogel, J. (2007). Paternity leave and fathers' involvement with their young children: Evidence from the American ECLS-B. Community, Work $\mathcal{E}$ Family, 10, (4), $427-453$.

Patridge, A. H., Gelber, S., Peppercorn, J., Sampson, E., Knudsen, K., Laufer, M., Rosenberg, R., Przypyszny, M., Rein, A., Winer, E. P. (2004). Web-based survey of fertility issues in young women with breast cancer. Journal of Clinical Oncology, 22, 4174-4183.

Quinn, G. P., Cadaparampil, S. T., Lee, J. H., Jacobsen, P.B., Bepler, G., Lancaster, J., Keefe, D. L., and Albrecht, T. L. (2009). Physician referral for fertility preservation in oncology patients: A national study of practice behaviors. Journal of Clinical Oncology, 27(35), 5952-5967.

Radloff, L.S. (1977). The CES-D scale: A self report depression scale for research in the general population. Applied Psychological Measurement, 1, 385-401.

Rieker, P. P., Fitzgerald, E. M., Kalish, L. A. (1990). Adaptive behavioral responses to potential infertility among survivors of testis cancer. Journal of Clinical Oncology, 8, 347 - 55.

Saito, K., Suzuki, K., Iwasaki, A., Yumura, Y., Kubota, Y. (2005). Sperm cryopreservation before cancer chemotherapy helps in the emotional battle against cancer. Cancer, 104,521-524.

Schover, L. R. (1999). Psychosocial aspects of infertility and decisions about reproduction in young cancer survivors: a review. Medical and Pediatric Oncology, 33:53-59. 
Schover, L.R., Rubicki, L.A., Martin, B.A., Bringelsen, K.A. (1999). Having children after cancer. A pilot survey of survivors' attitudes and experiences. Cancer, 86, 697-709.

Schover, L.R., Brey, K., Lichtin, A., Lipshultz, L.I., Jeha, S. (2002a). Knowledge and experience regarding cancer, infertility, and sperm banking in younger male survivors. Journal of Clinical Oncology, 20, 1880-1889.

Schover, L.R., Brey, K., Lichtin, A., Lipshultz, L. I., Jeha, S. (2002b). Oncologists' attitudes and practices regarding banking sperm before cancer treatment. Journal of Clinical Oncology, 2, 1890-1897.

Szasz, I. (1998). Masculine identity and the meanings of sexuality: A review of research in Mexico. Reproductive Health Matters, 6(12), 97-104.

Tschudin, S., Bitzer, J. (2009). Psychological aspects of fertility preservation in men and women affected by cancer and other life-threatening diseases. Human Reproduction Update, 1: 1-11.

U.S. Census Bureau. Press release: Father's day. http://www.census.gov/PressRelease/www/releases/archives/facts_for_features_special_editions/006794.html. Published June 12, 2006. Accessed March 11, 2010.

Ware, J. E., Sherbourne, C. (1992). The MOS 36-Item short-form health survey (SF-36): A conceptual framework and item selection. Medical Care, 30 (6), 473-483.

Wasserman, A. L., Thompson, E. I., Wilimas, J.A., and Fairclough, D.L. (1987). The psychological status of survivors of childhood/adolescent Hodgkin's Disease. American Journal of Diseases of Children, 141:626-631.

Wenzel, L., Dogan-Ates, A., Habbal, R., Berkowitz, R., Goldstein, D.P., Bernstein, M., Khusman, B.C., Osann, K., Newlands, E., Secki, M.J., Hancock, B., Cella, D. (2005). Defining and measuring reproductive concerns of female cancer survivors. Journal of the National Cancer Institute Monographs, 34, 94-98.

White, L., J. McQuillan, and A.L. Greil. (2006). Explaining disparities in treatment seeking: The case of infertility. Fertility \& Sterility, 85(4): p. 853-7.

Zanagnolo, V., Sartori, R., Trussardi, E., Pasinetti, B., Maggino, T. (2005). Preservation of ovarian function, reproductive ability and emotional attitudes in parents with malignant ovarian tumors. European Journal of Obstetrics $\mathcal{E}$ Gynecology and Reproductive Biology, 123, 235-243.

Zebrack, B. J., Casillas, J., Nohr, L., Adams, H., Zelter, L. K. (2004). Fertility issues for young adult survivors of childhood cancer. Psychooncology, 13, 689-699.

Zelter, L. K. (1993). Cancer in adolescents and young adults: Psychosocial aspects in longterm survivors. Cancer, 71(Suppl 10), 3463-3468. 


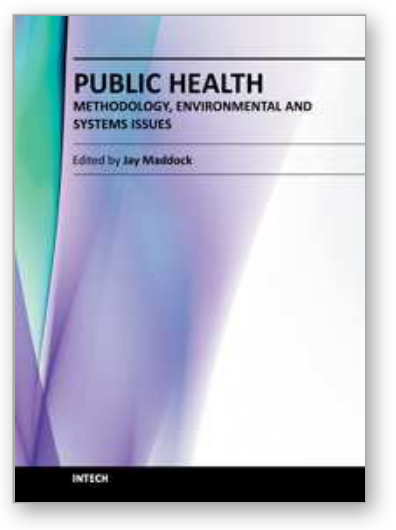

\author{
Public Health - Methodology, Environmental and Systems Issues \\ Edited by Prof. Jay Maddock
}

ISBN 978-953-51-0641-8

Hard cover, 432 pages

Publisher InTech

Published online 30, May, 2012

Published in print edition May, 2012

Public health can be thought of as a series of complex systems. Many things that individual living in high income countries take for granted like the control of infectious disease, clean, potable water, low infant mortality rates require a high functioning systems comprised of numerous actors, locations and interactions to work. Many people only notice public health when that system fails. This book explores several systems in public health including aspects of the food system, health care system and emerging issues including waste minimization in nanosilver. Several chapters address global health concerns including non-communicable disease prevention, poverty and health-longevity medicine. The book also presents several novel methodologies for better modeling and assessment of essential public health issues.

\title{
How to reference
}

In order to correctly reference this scholarly work, feel free to copy and paste the following:

Lisa Campo-Engelstein, Sarah Rodriguez and Shauna Gardino (2012). Saving More than Lives: A Gendered Analysis of the Importance of Fertility Preservation for Cancer Patients, Public Health - Methodology, Environmental and Systems Issues, Prof. Jay Maddock (Ed.), ISBN: 978-953-51-0641-8, InTech, Available from: http://www.intechopen.com/books/public-health-methodology-environmental-and-systems-issues/savingmore-than-lives-a-gendered-analysis-of-the-importance-of-fertility-preservation-for-cance

\section{INTECH}

open science | open minds

\author{
InTech Europe \\ University Campus STeP Ri \\ Slavka Krautzeka 83/A \\ 51000 Rijeka, Croatia \\ Phone: +385 (51) 770447 \\ Fax: +385 (51) 686166 \\ www.intechopen.com
}

\author{
InTech China \\ Unit 405, Office Block, Hotel Equatorial Shanghai \\ No.65, Yan An Road (West), Shanghai, 200040, China \\ 中国上海市延安西路65号上海国际贵都大饭店办公楼405单元 \\ Phone: +86-21-62489820 \\ Fax: +86-21-62489821
}


(C) 2012 The Author(s). Licensee IntechOpen. This is an open access article distributed under the terms of the Creative Commons Attribution 3.0 License, which permits unrestricted use, distribution, and reproduction in any medium, provided the original work is properly cited. 